\title{
Preço e estrutura da posse de escravos no termo de Vila do Carmo (Minas Gerais), 1713 - 1756
}

Price and Structure of Slave

Ownership in Vila do Carmo (Minas

Gerais), $1713-1756$

\section{Carlos Leonardo Kelmer Mathias}

Doutorando em História pela Universidade Federal do Rio de Janeiro

\begin{abstract}
Resumo
A partir da análise de todos os inventários post-mortem relativos aos anos de 1713 e 1756 presentes no $1^{\circ}$ e no $2^{\circ}$ ofício do Arquivo da Casa Setecentista de Mariana (366 no total), o artigo pretende estabelecer o padrão da posse de escravos no termo de Vila do Carmo - parte integrante da comarca de Vila Rica, capitania de Minas Gerais -, assim como analisar as flutuações do preço dos mesmos. Objetivando melhor compreender tal padrão e flutuações, por vezes o texto buscará empreender uma análise comparativa entre o recorte cronológico abordado e o período de 1750 até 1850.
\end{abstract}

\begin{abstract}
This article aims to analyze all post-mortem inventories found in the archive of the Casa Setecentista de Mariana, regarding the years 1713-1756 (a total of 366). It does so by establishing a pattern of slave ownership in Vila do Carmo - part of the judicial district of Vila Rica, in the captaincy of Minas Gerais -, as well as analyzing slave prices fluctuations. In order to better understand such patterns and fluctuations, a comparative analysis is attempted, between the data concerning the period under study studied and those from 1750 up to 1850.
\end{abstract}

Palavras-chave

escravos, demografia, mineração

\section{Keyword}

slaves, demography, mining 
FRAGOSO, João. Homens de grossa aventura: acumulação e hierarquia na praça mercantil do Rio de Janeiro, 1790-1830. Rio de Janeiro: Civilização Brasileira, 1998. p. 117-151.

Data mineral: "área legalmente demarcada para a exploração do ouro, de tamanho variável conforme o número de escravos de seu proprietário". CÓDICE Costa Matoso. Belo Horizonte: Fundação João Pinheiro, vol. II, 1999. Coordenação-geral de Luciano Raposo de Almeida Figueiredo e Maria Verônica Campos, p. 90. Arquivo Histórico Ultramarino, Minas Gerais, caixa 1, documento 2.

Uma braça equivalia a 4,84 m2. CODICE Costa Matoso, op. cit., p. 79.

Os escravos constituiam-se em peças-chave na contenção de revoltas, execução de diligência e na manutenção da governabilidade em Minas. Cf. KELMER MATHIAS Carlos Leonardo. "As condições da governabilidade: um refinado jogo de interesses na América Lusa da primeira metade do século XVIII". Revista de História, v. 14, p.3564. 2004. KELMER MATHIAS Carlos Leonardo. "De volta às condições da governabilidade, na busca de um equilibrio: notas acerca da sociedade mineira na primeira metade do sécuIo XVIII". REHB Revista Eletrônica de História do Brasil, v. 7, n. 2, p.20-36. 2005. KELMER MATHIAS, Carlos Leonardo. "O braço armado do senhor: recursos e orientações valorativas nas relações sociais escravistas, Minas Gerais na primeira metade do século XVIII". In: I/ Simpósio Escravidão e Mestiçagem: histórias comparadas. UFMG:FAFICH, Belo Horizonte, 2006.

LUNA, Francisco Vidal \& COSTA, Iraci del Nero da. "Demografia Histórica de Minas Gerais no Periodo Colonial". Revista Brasileira de Estudos Políticos, n.58, Belo Horizonte, UFMG, Janeiro., n॰58, 1984. Discutido por KELMER MATHIAS, Carlos Leonardo. A cor negra do ouro: circuitos mercantis e hierarquias sócias na formação da sociedade mineira setecentista, c. 1711 - c. 1756. Rio de Janeiro: PPGHIS, 2007 (Qualificação de doutorado).

\section{A estrutura da posse de escravos no termo de Vila do Carmo}

0 estudo da estrutura da posse de escravos presta-se a variados fins. Por exemplo, revela muito acerca do caráter mais geral da economia e dos valores sociais de uma dada sociedade. Esse tipo de estudo esteve na base das análises de João Fragoso que Ihe permitiu observar o contexto marcadamente escravista do Rio de Janeiro na passagem do século XVIII para o seguinte, a predominância das unidades produtivas do tipo camponês em Minas Gerais e São Paulo, e a coexistência do trabalho escravo, da peonagem e do campesinato no Rio Grande do Sul. ${ }^{1}$

No alvorecer da sociedade mineira, a posse de escravos detinha várias implicações, dentre as quais 0 acesso às datas minerais. ${ }^{2} 0$ parágrafo quinto do Regimento de 19 de abril de 1702 regulava a distribuição dos achados auriferos. Uma vez tendo tomado conhecimento de alguma descoberta, o superintendente das Minas deveria ordenar ao guarda-mor que fizesse "medir o comprimento deles para saber as braças que tem efeito". Em seguida, faria "a repartição das datas, dando em primeiro lugar data a pessoa que descobriu o ribeiro", a segunda cabia a Real Fazenda, e a terceira novamente ficava ao critério do descobridor, podendo escolher no local que melhor de aprouvesse, "por convir que os descobridores sejam em tudo favorecidos e estendam os ânimos a fazerem muitos descobrimentos"3.

Ao término desta repartição, as demais datas seriam concedidas a outros homens "regulando-se pelos escravos que cada um tiver que em chegando a doze escravos e daí para cima, fará repartição de uma data de trinta braças, conforme o estilo; e aquelas pessoas que não chegarem a ter doze escravos thes serão repartidas duas braças e meia por cada escravo"4. Não obstante, a posse de escravos também implicava em distinção social e era signo de poder. 5

Sabe-se que a análise da estrutura da posse de escravos nos termos de Vila do Carmo e de Vila Rica em 1718 apontou uma distribuição relativamente homogênea dos escravos dentre os diversos plantéis. A variação maior ficou por conta da participação dos proprietários conforme as faixas de escravos. ${ }^{6}$ 0 mesmo perfil pode ser percebido para os demais termos da capitania entre finais da década de 1710 e início da seguinte, conforme demonstra a tabela 1. Essa moderada equivalência, conquanto encerre uma dada desigualdade, revela um quadro obscuro acerca das diferentes formas de acesso ao cativo, mesmo por que a fonte base que serviu para a construção da tabela é de natureza fiscal. Dessa forma, a distribuição dos escravos pelos plantéis mostrase bastante desigual quando o foco recai nos proprietários dos mesmos. 0 que levaria a crer na existência de uma considerável concentração dos escravos em poder de poucos. Que se observe a tabela abaixo.

Tabela 1 - Estrutura da posse de escravos em alguns termos da capitania de Minas Gerais, 1717-1722

\begin{tabular}{|l|c|c|c|c|c|c|c|c|}
\hline Faixa & \multicolumn{2}{|c|}{$\begin{array}{c}\text { São João Del Rei, } \\
1717\end{array}$} & \multicolumn{2}{|c|}{ Vila Rica, 1721 } & \multicolumn{2}{c|}{ Sabará, 1721 } & \multicolumn{2}{c|}{$\begin{array}{c}\text { São José Del Rei, } \\
1722\end{array}$} \\
\hline & A & B & A & B & A & B & A & B \\
\hline $1-4$ & 53,55 & 18,22 & 56,8 & 20,24 & 56,91 & 19,58 & 56,07 & 18,59 \\
\hline $5-9$ & 25,72 & 25,47 & 25,1 & 26,67 & 21,93 & 22,26 & 24,09 & 23,89 \\
\hline $10-19$ & 14,97 & 30,72 & 13,09 & 28,04 & 15,57 & 31,48 & 12,15 & 23,65 \\
\hline $20-49$ & 5,38 & 20,8 & 4,72 & 22,07 & 4,93 & 20,61 & 6,88 & 26,69 \\
\hline$\geq 50$ & 0,38 & 4,79 & 0,29 & 2,98 & 0,66 & 6,07 & 0,81 & 7,18 \\
\hline
\end{tabular}

Fonte: BOTELHO, Tarcísio Rodrigues. "População e Escravidão nas Minas Gerais, c. 1720". In: XII Encontro da Associação Brasileira de Estudos de População. Caxambu, 2000, 48-53. Legenda: A - \% de proprietário da faixa; B - \% de escravos da faixa. 
7

LUNA, Francisco Vidal \& COSTA, Iraci del Nero da. "Demografia Histórica de Minas Gerais no Periodo Colonial". In: Revista Brasileira de Estudos Politicos, n.58, Belo Horizonte, UFMG, Janeiro, 1984. p. 17-18.
Notando a faixa dos indivíduos aptos a receberem as melhores datas auriferas após o descobridor e a Real Fazenda, percebe-se que nunca mais de 22\% dos proprietários integravam a faixa. Em 1717, o termo de São João d'El Rei apresentava tão somente 20,73\% de plantéis acima de dez escravos, os quais, por sua vez, respondiam por $56,31 \%$ dos cativos. 0 mesmo padrão é percebido para as demais localidades. Em Vila Rica de 1721, as proporções seriam 18,1\% e 53,09\%; Sabará, 21,16\% e 58,16\%. A maior concentração coube ao termo de São José, com 19,84\% e 57,52\%. A grande maioria dos proprietários ou resignavam-se com o acesso a menores e piores datas, ou voltavam suas atividades para o mercado de abastecimento interno - quer de unidades mineradoras, quer de indivíduos não vinculados à exploração da terra, como viandantes os quais atuavam na capitania, lojistas etc. Ademais, observa-se uma forte concentração na posse de escravos.

Porém, a análise da estrutura da posse de escravos a partir das listas voltadas para a arrecadação dos quintos - principal documentação a partir da qual Tarcísio Botelho depreendeu suas análises - encerra alguns problemas. Dentre eles, destaco a possibilidade de sonegação do número de escravos possuidos por um determinado sujeito, uma vez que o valor dos quintos era calculado com base na quantidade de escravos de cada minerador. Nesse sentido, os inventários post-mortem servem melhor ao estudo da estrutura de posse de escravos. Para além, permitem um acompanhamento ao longo do tempo do comportamento dessa estrutura, o que não é possivel a partir das listas para os quintos. Por se tratar de uma fonte homogênea, maciça e reiterativa no tempo, permite uma seriação menos disforme quando comparada com tais listas. Vale lembrar, conforme a lista de proprietários elaborada para a cobrança dos quintos no termo de Vila do Carmo em 1718, 20,99\% dos aptos a receberem trinta braças nas datas auriferas detinham $56,88 \%$ dos cativos. ${ }^{7}$ As diferenças na estrutura da posse de escravos conforme os inventários e as listas podem ser observadas a partir da tabela abaixo.

Tabela 2 - Estrutura da posse de escravos no termo de Vila do Carmo, 1713-1756

\begin{tabular}{|c|c|c|c|c|c|c|}
\hline \multirow[t]{2}{*}{ Faixa } & \multicolumn{2}{|c|}{$1713-1730$} & \multicolumn{2}{|c|}{$1731-1740$} & \multicolumn{2}{|c|}{$1741-1756$} \\
\hline & A & $\mathrm{B}$ & A & $\mathrm{B}$ & $\mathrm{A}$ & $\mathrm{B}$ \\
\hline $1-5$ & 15,38 & 2,7 & 24,42 & 4,08 & 28,48 & 4,2 \\
\hline $6-10$ & 30,77 & 13,3 & 20,93 & 8,9 & 21,85 & 8,61 \\
\hline $11-20$ & 20,51 & 17 & 18,6 & 12,56 & 18,54 & 14,86 \\
\hline $21-40$ & 21,8 & 32,5 & 20,93 & 28,22 & 20,53 & 32,53 \\
\hline $41-$ & 11,54 & 34,5 & 15,12 & 46,24 & 10,6 & 39,8 \\
\hline Gini & \multicolumn{2}{|c|}{0,452} & \multicolumn{2}{|c|}{0,516} & \multicolumn{2}{|c|}{0,549} \\
\hline Média de escravos & \multicolumn{2}{|c|}{18,02} & \multicolumn{2}{|c|}{21,67} & \multicolumn{2}{|c|}{18,93} \\
\hline №. de inventários & \multicolumn{2}{|c|}{78} & \multicolumn{2}{|c|}{86} & \multicolumn{2}{|c|}{151} \\
\hline
\end{tabular}

Fonte: Arquivo da Casa Setecentista de Mariana, Inventário Post-mortem, $1^{\circ}$ e $2^{\circ}$ oficios. Legenda: A - \% de proprietário da faixa; B - \% de escravos da faixa.

A principal disparidade que emana da tabela acima consiste no número de proprietários em condições de receber trinta braças. No primeiro periodo, esses indivíduos representavam 53,85\%, respondendo por $84 \%$ dos escravos inventariados. Ao longo da primeira metade do século XVIII, o padrão não sofreu maiores alterações. Entre 1731 e 1740, as porcentagens foram de $54,65 \%$ e $87,02 \%$; no último momento analisado, 49,67\% e 87,19\%, indicando um pequeno aumento na concentração dos escravos, em concor- 
dância com o apresentado pelo Índice de Gini. Ademais, a tabela revela uma alta média de escravos por plantel, mesmo nas primeiras décadas do século XVIII, conjuntura na qual o preço dos cativos foram os mais elevados no termo até por volta de 1830. Estamos de fronte a um quadro no qual a maior parte dos detentores de escravos possuiam um plantel com no mínimo onze escravos, sendo que nunca menos de $31 \%$ dos inventariados eram grandes senhores, com 21 ou mais cativos. Além de possuir acesso aos escravos, a maior parte dos inventariados os podiam comprar em número razoavelmente elevado, não obstante o alto preço dos mesmos.

Vale notar, o perfil da posse de escravos não sofreu maiores alterações conforme o aumento da produção aurifera (ver gráfico 1). Porém, na medida em que a extração aurifera perdia rendimento, a concentração acirrou-se.

Tabela 3 - Estrutura da posse de escravos no termo de Vila do Carmo, 1750-1850

\begin{tabular}{|l|c|c|c|c|c|c|}
\hline \multicolumn{1}{|c|}{ Faixa } & \multicolumn{2}{|c|}{$1750-1770$} & \multicolumn{2}{c|}{$1780-1810$} & \multicolumn{2}{c|}{$1820-1850$} \\
\hline & A & B & A & B & A & B \\
\hline $1-5$ & 41,4 & 7,3 & 45,4 & 13,2 & 46,6 & 13,1 \\
\hline $6-10$ & 6,9 & 4,2 & 26,4 & 19,3 & 25,6 & 20,3 \\
\hline $11-20$ & 34,5 & 41 & 19,1 & 27,2 & 19,9 & 32,4 \\
\hline$\geq 21$ & 17,2 & 47,5 & 9,1 & 40,3 & 7,9 & 34,2 \\
\hline
\end{tabular}

Fonte: ALMEIDA, Carla. Alterações nas unidades produtivas mineiras: Mariana - 1750- 1850. Niterói: UFF, 1994, p. 136 (Dissertação de Mestrado).

Legenda: A - \% de proprietário da faixa; B - \% de escravos da faixa.

Até por volta de 1770, momento no qual a produção aurifera, embora em queda contínua, ainda apresentava um rendimento satisfatório, o perfil dos proprietários de 11 ou mais cativos não sofreu maiores variações quando comparado aos períodos precedentes. Tais homens representavam 51,7\% dos proprietários, detendo 88,5\% dos escravos. Todavia, o empobrecimento da sociedade pode ser detectado nas faixas de 1 a 10 escravos. Entre 1713 e 1770 , esses senhores variaram entre $43,35 \%$ e $50,33 \%$, cujos cativos estavam compreendidos entre $11,5 \%$ e $16 \%$ do total (observar conjuntamente tabelas 2 e 3). Pormenorizando, os plantéis de 1-5 escravos passaram por um aumento de 45,36\% entre 1741-1756 e 1750-1770, concomitantemente a uma diminuição da ordem de $68,42 \%$ dos plantéis de 6-10 nos mesmos períodos. Tal fenômeno pode ser percebido nos demais plantéis. A faixa de 11-20 escravos conheceu um aumento de $86,08 \%$, ao passo que a faixa acima de 21 escravos descreu 55,25\%. Uma nova redução é percebida quando se compara meados do setecentos com o final do século XVIII e início do seguinte. Ocorre uma queda escalonada desde os plantéis maiores até os menores. A inflexão na produção aurifera deu-se por volta de 1744 , seus reflexos podem ser claramente observados provavelmente já na década de 60.

Dentre os reflexos que respeitam ao arrefecimento na produção de ouro estava a maior concentração de escravos percebida fundamentalmente a partir de 1780. Na falta de indicadores mais precisos acerca do nivel de concentração para os dados apresentados na tabela 3 - como o Índice de Gini, por exemplo -, podemos perceber que entre 1780 e 1810, não obstante tenham conhecido uma redução de $45,45 \%$ em relação ao período anterior, os plantéis com mais de onze escravos detinham 67,5\% dos cativos, um abaixamento de apenas $23,72 \%$. Ou seja, a queda percentual dos escravos representados por essas faixas foi bastante inferior à diminuição da participação das mesmas frente aos demais plantéis, o que indica uma maior concentração na estrutura da posse de escravos no intervalo de 1780-1810 
GUIMARÃES, Carlos Magno; REIS, Liana Maria. "Agricultura e escravidão em Minas Gerias, 1700-1750". Revista do Departamento de História da UFMG, Belo Horizonte, v. 1, n. 2 p.15. 1986.

Entre 1750-1770, o número médio de cativos em uma unidade produtiva agropecuária e mineradora era de 24 . Essa foi a maior média de escravos em um tipo de unidade produtiva registrado por Carla Almeida para o termo de Vila do Carmo entre 1750-1850. ALMEIDA, Carla. Alterações nas unidades produtivas mineiras: Mariana - 1750-1850. 1994. Dissertação (Mestrado) Niterói: Universidade Federal Fluminense, 1994. p. 194

10

Ibidem, p. 136

11

BERGAD, Laird. Escravidão e história econômica: demografia de Minas Gerais, 1720-1888. São Paulo: EDUSC, 2004. p. 278.

12

ALMEIDA, Carla. Op.Cit. p. 194. quando comparada com o período anterior, no qual a produção aurifera ainda apresentava niveis satisfatórios de extração. A sociedade mineradora no termo de Vila do Carmo era menos desigual do que aquela fundamentalmente baseada nas atividades agropecuárias.

Cumpre registrar, nem todos os inventários arrolados na tabela 2 registraram posse de datas ou lavras minerais entre seus bens de raiz. Dos 315 inventariados, apenas 68, ou 21,58\%, exerciam ocupações de extração. Por outro lado, 180, ou 57,14\%, detinham na agricultura sua principal atividade, sendo 54 igualmente proprietários de datas ou lavras. De resto, 25 , ou 7,93\%, consistiam senhores de engenho, dos quais 12 também possuiam terrenos auriferos. Em outras palavras, observa-se um cenário no qual a grande maioria dos proprietários de escravos produzia para o mercado de abastecimento interno. Esse quadro era amplamente condizente com as características mais gerais da agricultura mineira. Segundo Carlos Guimarães e Liana Reis, a "agricultura mineira do século XVIII estava perfeitamente adaptada às condições de fertilidade e relevo existentes na capitania", sendo que "junto a uma lavra podia se estabelecer uma lavoura, mesmo porque não há homogeneidade na formação do terreno na área das Minas", o que "reflete a existência de terras agricultáveis mesmo nas áreas onde predomina um tipo de terreno não adequado à agricultura" 8 . Donde se percebe a maior alocação dos escravos em unidades produtivas voltadas mais para a agricultura do que para a mineração.

Sem embargo, há de ressalvar que, em média, as unidades produtivas nas quais se fez presente a mineração eram aquelas com as maiores concentrações de escravos. Por via de regra, tais propriedades alocavam cerca de 40 cativos. Para os padrões do termo de Vila do Carmo, trata-se da maior média de concentração de escravos em uma dada unidade produtiva até pelo menos $1850 .{ }^{9}$ Evidentemente, nem todos os cativos eram empregados na mineração, mesmo por que, dos 68 inventários com atividades de mineração, apenas três, 4,41\%, não possuiam quer uma roça, quer um engenho corrente e moente. De todo modo, os maiores proprietários de escravos na história do termo de Vila do Carmo não foram os senhores de engenho, mas sim os proprietários de datas, lavras e veios auriferos.

Essa constatação torna-se mais evidente observando o número médio de cativos nas unidades produtivas especificamente agricolas e naquelas detentoras de engenho. No que concerne as primeiras, a média de escravos não passou de 14. Já os engenhos, registram 31 cativos. Novamente, estamos diante das maiores médias nunca atingidas no porvir do termo de Vila do Carmo. ${ }^{10}$ Vale destacar, trata-se de uma conjuntura em que o preço dos cativos era consideravelmente superior àqueles registrados após 1756 . A recuperação dar-se-ia somente no início do século XIX11, quando a concentração de escravos nas unidades produtivas registrou as mais baixas médias. ${ }^{12}$

Mais revelador ainda é o número total de escravos agregado por cada unidade produtiva. Tendo sempre em conta que as mineradoras igualmente exerciam atividades agricolas e detinham engenho corrente e moente, essas unidades reuniram 2.741 cativos, contra os 440 daquelas detentoras somente de engenhos e os 1.748 das unicamente agrícolas. Nesses termos, dos 339 inventários pesquisados, as unidades produtivas mineradoras responderam por 20,05\%, e dos 5.628 escravos arrolados, essas unidades representaram 48,7\%. Fica claro que a ampla maioria da população estava à margem da atuação direta na extração aurífera. Contudo, sua participação na mesma dava-se por intermédio do mercado de abastecimento 
13

SCHWARTZ, Stuart. Segredos internos: engenhos e escravos na sociedade colonial. São Paulo: Companhia das Letras, 2005. p. 364.

14

COSTA, Iraci del Nero da. "Nota sobre a posse de escravos nos engenhos e engenhocas fluminenses (1778)". Revista do IEB, São Paulo, Instituto de Estudos Brasileiros da Universidade de São Paulo, (28):111-113, p. 2-3, 1988

15

ALMEIDA, Carla. Alterações nas unidades produtivas mineiras: Mariana - 1750-1850. 1994. Dissertação (Mestrado) Niterói: Universidade Federal Fluminense, 1994. p. 137.

16

Ibidem, p.186 e 188 . interno - ou das unidades mineradoras, ou dos demais segmentos residente-atuantes na capitania de Minas.

Não se observa no termo de Vila do Carmo grandes propriedades escravas, o número médio de 40 escravos para as maiores unidades produtivas não chega a ser uma marca muito considerável quando comparada, por exemplo, com os engenhos baianos de início do século XIX. No que respeita a esta matéria, as diferenças são apreciáveis. Entre 1816 e 1817, absolutamente nenhum engenho na Vila de São Francisco possuía plantéis com menos de vinte escravos, sendo que $42,5 \%$ dos proprietários eram senhores de cativos compreendidos na faixa de 60 a 99. A média de escravos em um engenho na Vila de São Francisco era de 70, e na Vila de Santo Amaro 62 escravos. ${ }^{13}$ Por outro lado, em dezessete ocasiões o termo de Vila do Carmo apresentou unidades produtivas mineradoras com menos de vinte escravos; nem mesmo os senhores de engenho fugiram a esse perfil.

Em termos de média de posse de escravos, essas unidades de mineração estavam mais em conformidade com os engenhos fluminenses de finais do século XVIII. Em 1778, um engenho no Rio de Janeiro possuía em média 36 escravos, e as engenhocas cerca de 11. Em 1804, um engenho de açúcar em Campinas apresentava uma média de 21 escravos; em Itu, 25 e em São Sebastião, 32. Contudo, o único Índice de Gini a ultrapassar 0,38 foi o relativo à capitania do Rio de Janeiro, com 0,522.14 Para as unidades mineradoras no termo de Vila do Carmo, o Índice foi de 0,377. Do posto, percebe-se uma relativa homogeneidade na estrutura da posse de escravos nos engenhos baianos (Índice de 0,21 para a Vila de São Francisco e de 0,3 para a Vila de Santo Amaro), paulistas e nas unidades produtivas mineradoras no termo de Vila do Carmo. A heterogeneidade coube aos engenhos fluminenses.

Se for correto afirmar que a maior presença de pequenos e médios plantéis, no final do século XVIII e decorrer do XIX, estava em conformidade com as atividades agropecuárias, uma vez que "embora capazes de gerar dinamismo e certo grau de acumulação" essas unidades produtivas eram "muito menos lucrativas e exigem um menor contingente de mãode-obra que a mineração"15, então haveriamos de crer, conforme a tabela 2, que a agropecuária no decorrer da primeira metade do século XVIII não era lá muito difundida. Por bem, a queda percebida no final do século XVIII evidencia o empobrecimento das camadas mais baixas da sociedade. Em 1750-1770, o monte-mor médio da faixa até 1.000 libras era de 445, passando para 264 no período seguinte. Igualmente, faixa de 1.001 a 3.000 libras sofreu uma queda no valor médio de seu monte-mor no mesmo momento. A exceção ficou por conta dos mais ricos, passando de um monte médio de 5.598 libras para 8.421. Nas palavras da autora, "os níveis da desigualdade entre as pessoas livres aumentaram muito no decorrer do período e tenderam para uma extrema polarização da riqueza e da pobreza"16.

Nesses termos, a maior concentração dos cativos nos plantéis acima de onze escravos no termo de Vila do Carmo na primeira metade do século XVIII não evidenciava uma maior difusão de potenciais mineradores aptos a receber as melhores braças. Tampouco era indicativo de uma concentração de riqueza. Ao contrário. Em um contexto no qual o preço do cativo atingiu os maiores picos nunca vistos até o início do século XIX - momento no qual a concentração de riqueza revelou-se, de fato, elevada -, a posse de escravos era viabilizada em função do acesso indireto ao ouro por parte dos cerca de $80 \%$ diretamente excluídos dos exercícios extrativos. E tal acesso dava-se por meio das atividades agropecuárias voltadas para o abastecimento interno. 
17

KELMER MATHIAS, Carlos Leonardo. A cor negra do ouro: circuitos mercantis e hierarquias sócias na formação da sociedade mineira setecentista, c. 1711 - c. 1756. Rio de Janeiro: PPGHIS, 2007 (Qualificação de doutorado), capitulo 2.
18

Arquivo da Casa Setecentista de Mariana, Livro de Nota 27, Escritura de Alforria e Liberdade, 22/09/1727.

19

Arquivo da Casa Setecentista de Mariana, Livro de Nota 27-29, Escritura de Compra e Venda.

20

Arquivo da Casa Setecentista de Mariana, Inventário Post-mortem, $1^{\circ}$ e $2^{\circ}$ ofícios.
Cumpre registrar, não podemos perder de vista que na primeira metade do século XVIII o escravo era a principal garantia de acesso ao crédito no termo de Vila do Carmo. ${ }^{17}$ Para além, vários eram os militares os quais obravam em nome de El-Rei na capitania. A eles, não era possível prescindir de escravos, seu braço armado. 0 ouro, embora produzido por poucos, figurava ao alcance de muitos; como a pose de escravos cuidou de demonstrar.

\section{O Preço dos Escravos}

Os inventários não são de forma alguma as melhores fontes para tratar dos preços dos escravos. Por via de regra, os valores apresentados eram inferiores àqueles aferidos através das escrituras de compra e venda, de alforria ou mesmo quando um cativo era hipotecado com um dado propósito. Ocorria do inventariante - normalmente um parente do inventariado, como cônjuge, filho, etc. - delegar ao escravo um preço muito abaixo de seu valor de mercado. Talvez o motivo para tanto resida nos desgastes sofridos pelo cativo ao longo dos anos, o que concorreria para a diminuição do seu valor - mesmo que o bem inventariado não apresentasse maiores agravos corporais ou mentais. Seja como for, os preços arrolados nos inventários postmortem constituiram-se nos menores até então pesquisados.

Por outro lado, conquanto impróprios para uma aproximação mais fidedigna acerca dos valores dos cativos, os inventários a princípio servem como indicativos relativamente confiáveis das tendências mais gerais do movimento do preço dos escravos. Igualmente, não podemos atribuir às escrituras de compra e venda o ônus exclusivo de reportar o quanto se pagava por um escravo em uma dada sociedade. No que tange ao termo de Vila do Carmo nas suas primeiras décadas, esse tipo de documento não dá conta, por exemplo, nem do sexo e nem da idade do escravo, fatores os quais em muito influenciavam no preço. Dessa forma, a melhor maneira de nos aproximarmos do valor dos cativos dá-se através do cruzamento das fontes.

Não raramente, no momento de se acordar o valor da alforria de um dado escravo, comumente o preço estabelecido era o de mercado. Logicamente, há casos em que laços outros acarretavam na diminuição do preço. Por exemplo, em 22 de setembro de 1727, o capitão André Gonçalves Chaves alforriou a crioula Joana Ferreira Soares, sob a condição de "o servir enquanto estivesse nestas minas ou em outra qualquer parte da América", mediante o pagamento de $120 \$ 000 . .^{18}$ Nesse mesmo ano, o preço médio de um escravo transacionado no termo de Vila do Carmo era de $292 \$ 335.19$ Mesmo os inventários trazem um preço maior. Entre 1726-1730, um escravo adulto costumava ser avaliado em $193 \$ 475.20$ Todavia, casos como estes são exceções. Conforme se verá, havia uma proximidade bastante razoável entre o preço pago por um escravo no momento de sua alforria e aquele obtido nos livros de nota, donde se conclui que a maioria dos escravos pautados nas escrituras de compra e venda presentes nos livros de notas deveriam ser adultos, entre 14 e 45 anos. Vale observar o a tabela 4.

Tabela 4 - Preços médios dos escravos no termo de Vila do Carmo,1711-1730

\begin{tabular}{|l|c|c|c|c|}
\hline \multicolumn{1}{|c|}{ Fonte } & $1711-1715$ & $1716-1720$ & $1726-1730$ & Geral \\
\hline $\begin{array}{l}\text { Escrituras de alforria e liberdade } \\
\text { (adultos) }\end{array}$ & $369 \$ 864$ & $366 \$ 477$ & $349 \$ 831$ & $359 \$ 008$ \\
\hline Escrituras de compra e venda & $369 \$ 405$ & $316 \$ 388$ & $290 \$ 416$ & $333 \$ 335$ \\
\hline
\end{tabular}

Fonte: ACSM, Livro de Nota 01-15 e 25-35, Escritura de Alforria e Liberdade e Escritura de Compra e Venda. 


\section{1}

ALMEIDA, Carla. Alterações nas unidades produtivas mineiras: Mariana - 1750-1850. 1994 Dissertação (Mestrado) Niterói: Universidade Federal Fluminense, 1994. p. 178 e BERGARD, Laird. Escravidão e história econômica: demografia de Minas Gerais, 1720-1888. São Paulo: EDUSC, 2004. p. 278.

\section{2}

A primeira forma de arrecadação dos quintos foi definida em 24 de julho de 1711, e recebeu a denominação popular de sistema de bateias. Consistia no pagamento de 10 oitavas sobre cada bateia (prato côncavo utilizado na mineração). Na realidade, pagava-se sobre cada escravo. Essa proposta foi rejeitada pelos mineiros, os quais ofereceram em troca a cota de trinta arrobas divididas consoante à produção aurifera de cada comarca, ficando a cargo das câmaras determinarem o valor a ser pago por cada contribuinte. Este sistema perdurou de 1714 até 1719, quando se determinou a instalação das Casas de Fundição e Moeda, sendo que, em 1718, a cota das trinta arrobas foi reduzida para vinte e cinco acrescida do direito de cobrança das entradas. Em 1722, a cota foi elevada para trinta e sete arrobas. Com o estabelecimento das Casas de Fundição em 1725, o ouro passou a ser fundido em barras, das quais se descontava o quinto. Em 1730, o então governador D. Lourenço de Almeida reduziu, sem consentimento régio, o valor do quinto de $20 \%$ para $12 \%$. Em 1732, a taxa voltou para os $20 \%$ originais. Em 1735, entra em vigor o sistema de capitação. Tal sistema consistia no pagamento semestral realizado nas casas de intendência do ouro nos seguintes valores: duas oitavas e doze vinténs sobre cada escravo forro ou oficial mecânico; vinte e quatro oitavas sobre loja grande, dezesseis sobre médias e oito sobre pequenas. A capitação esteve atuante entre julho de 1735 e junho de 1751. Por alvará régio de 1750 , as Casas de Fundição foram reabertas. Em 1751, regulamentadas, determinando o pagamento da cota de cem arrobas anuais. Em caso de o quinto não atingir a cifra, o restante seria recolhido por intermédio da derrama. As variações na relação oitava/real obedeceram tais alterações. Até 1725, uma oitava valia $1 \$ 500$. Com o estabelecimento das Casas de fundição, uma oitava passou a equivaler $1 \$ 200$. Em 1730, D. Lourenço diminui a porcentagem dos quintos, uma oitava subiu para $1 \$ 320$. Em 1732 , retorna-se à porcentagem de $20 \%$, uma oitava novamente passa a valer $1 \$ 200$. Em 1735, adotase o sistema da capitação, uma oitava retorna a corresponder a $1 \$ 500$. Por fim, em 1751 entra em vigor a forma definitiva de recolhimento do quinto, via Casa de Fundição, e a equivalência da oitava em real ficou definitivamente acordada em $1 \$ 200$. Sobre essas variações ver CÓDICE Costa Matoso, Belo Horizonte: Fundação João Pinheiro, Vol. II, 1999; e ROMEIRO, Adriana \& BOTELHO, Ângela. . Dicionário histórico das Minas Gerais: periodo colonial. Belo Horizonte: Autêntica, 2003.
Observa-se uma paridade bastante razoável entre os valores apresentados. Muito possivelmente, a inferioridade nos preços dos escravos presentes nas escrituras de compra e venda a partir de 1716 em relação aos alforriados justifica-se em função de nem todos os cativos transacionados terem sido adultos, não obstante a grande maioria estivesse provavelmente inserida entre quinze e quarenta e cinco anos. De qualquer modo, em ambas as fontes o que se percebe é uma tendência, mesmo que leve, de queda no preço dos escravos. Essa quase insignificante redução nos valores - talvez seja melhor trabalhar com a idéia de relativa estabilidade dos preços - estava relacionada à enorme capacidade de absorver a oferta de cativos, fruto de uma grande demanda ainda presente em finais da década de 1720. No atual estágio da pesquisa, não é possivel determinar, com precisão, 0 exato momento de arrefecimento de tal procura. A concordar com os dados apresentados pelos inventários post-mortem, essa inflexão deu-se em meados da década de 1730 .

Vale comparar a tabela acima com as 2 e 3 . Sabe-se que os preços apresentados acima foram os maiores registrados no termo de Vila do Carmo até o alvorecer do século XIX. Em tal conjuntura, a estrutura da posse de escravos apresentou um padrão cuja essência manteve-se até a década de 1780. Haja vista que o preço dos cativos no termo de Vila do Carmo entrou em curva decrescente até meados da década de 178021, a manutenção da estrutura de posse desde 1713 até 1770 revela-se algo intrigante. Na verdade, a curva da produção aurifera dá conta de explicar a questão.

Observando o gráfico 1, podemos notar que o nível da produção aurifera em 1774 é exatamente o mesmo daquele apresentado em 1715. Ou seja, as transformações econômicas vividas pela comarca de Vila Rica foram antes de ordem política do que fruto das oscilações na produção aurifera. Dentre as principais intervenções na economia da capitania, destaco as variações na forma da cobrança dos Reais Quintos, o que acarretou alterações na relação oitava/real até 1751.22 Logicamente, não cabe desconsiderar os impactos econômicos e sociais da sempre contínua ascensão da extração aurifera seguida da igualmente ininterrupta involução da mesma a partir de meados da década de 1740 .

Gráfico 1 - Curva da produção aurifera na capitania de Minas Gerais, 1700-1799

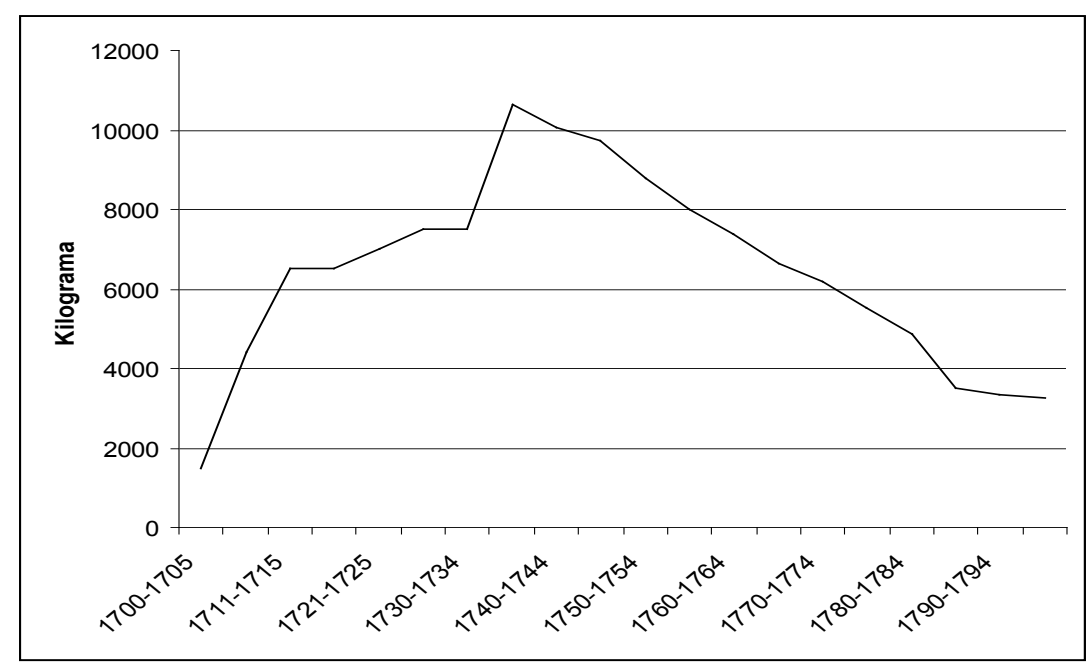

Fonte: PINTO, Virgílio Noya. O ouro brasileiro e o comércio anglo-português: uma contribuição aos estudos da economia atlântica no século XVIII. São Paulo: Ed. Nacional, 1979, p. 114. 
23

CARRARA, Ângelo. Agricultura e pecuória na Capitania de Minas Gerais, 1674-1807. 1997. Tese (Doutorado). Rio de Janeiro: IFCS, Universidade Federal do Rio de Janeiro, 1997. p. 32. [grifos do autor].
Em realidade, a estrutura da posse de escravos não correspondeu às interferências da política econômica metropolitana, mas sim aos próprios níveis da produção aurifera. Vale lembrar, o tempo de duração de todas as empresas mineradoras era determinado pelo rendimento das lavras (...) é exatamente isso o que determinava o tamanho da 'fábrica' (particularmente o número de escravos), e os gastos com ela (alimentação e vestuário dos escravos e manutenção/reposição das ferramentas, por exemplo) - era a produção mineral o que sustinha e permitia a reprodução das unidades de produção escravistas. $^{23}$

A estrutura da posse de escravos apresentou uma forte alteração no exato momento em que os niveis da produção aurifera não mais demandavam o padrão até então vigente. Não obstante tão somente 20,05\% dos inventários terem apresentado lavras ou datas, já vimos que os demais segmentos sociais interagiam com a extração de ouro mesmo que de forma indireta. Com que então o rendimento das lavras acabou por influenciar a estrutura da posse de escravos para além das unidades de produção mineradoras. Como não poderia deixar de ser, a queda nas atividades extrativas apresentadas a partir de 1750 não deixou de causar impacto. Basta observar o aumento da faixa de 1-5 escravos concomitante à diminuição da faixa de 6-10 em meados do século XVIII (tabelas 2 e 3), reflexo do início do processo de pauperização dos mais baixos segmentos da população.

Caso a estrutura da posse de escravos estivesse em diapasão com as interferências da política econômica proveniente do reino, deveríamos observar maiores alterações no padrão dos plantéis fundamentalmente na primeira metade do setecentos, conjuntura na qual deram-se todas as variações na forma de cobrança dos Reais Quintos e na relação oitava/real. Mas não é o que se observa. Diga-se de passagem, a meu ver essa constatação reforça ainda mais a opção por trabalhar com o real no valor único de $1 \$ 200$ a oitava, pois dessa forma é possivel perceber com bastante clareza o comportamento do preço dos escravos consoante os niveis da produção aurífera, cujo rendimento foi o principal fator a reger o padrão da posse de cativos.

Antes de oferecer o desempenho dos preços dos escravos tanto respeitando as variações no valor da oitava, como deflacionando o real - o que será feito com base nos inventários post-mortem -, friso o fato de estarmos lidando com os menores valores oferecidos por todas as fontes pesquisadas. Já apresentei o quanto se pagava por um escravo adulto consoante as escrituras de alforria e liberdade e as de compra e venda (tabela 4). Passo a fazê-lo conforme os valores estimados dos escravos dados como garantia ao pagamento do contrato das entradas das comarcas de Vila Rica, Rio das Mortes e Rio das Velhas por parte dos arrematantes em 1718.

Vários foram os bens postos em hipoteca pelos fiadores e pagadores da arrematação, dentre os quais: engenhos, sítios, casas, dividas ativas, etc. Dos duzentos e vinte escravos os quais concorreram na hipoteca, foi possivel identificar idade, naturalidade, sexo e preço para cento e setenta deles. Embora essas estimativas de preço possam conter algumas distorções em função da finalidade para qual foram estipuladas - servir de garantia ao pagamento do contrato -, aos valores dos escravos sempre se seguiram expressões como "não valeria menos de", "e valeriam (...) mais ou menos", "podendo bem valer", "valeriam um por outro por serem mineiros", isto é, tais preços expressavam ou o valor mínimo, ou médio do escravo. A tabela 5 anuncia os dados. 
Tabela 5 - Sexo, naturalidade, idade e valor médio dos escravos hipotecados na arrematação do contrato dos dízimos reais das três comarcas da capitania de Minas do Ouro, 1718

\begin{tabular}{|l|l|l|l|c|c|}
\hline Linha & \multicolumn{1}{|c|}{ A } & \multicolumn{1}{|c|}{ Sexo } & \multicolumn{1}{c|}{ Naturalidade } & Idade & B \\
\hline 01 & 32 & Masculino & Africanos e crioulos & 12 a 38 & $282 \$ 000$ \\
\hline 02 & 19 & Feminino & 18 africanas e 1 crioula & 12 a 38 & $258 \$ 000$ \\
\hline 03 & 9 & Masculino & Minas & 22 a 29 & $276 \$ 000$ \\
\hline 04 & 8 & Masculino & Minas & 19 a 31 & $264 \$ 000$ \\
\hline 05 & 9 & Masculino & 8 africanos e 1 crioulo & 21 a 32 & $300 \$ 000$ \\
\hline 06 & 9 & Masculino & 8 africanos e 1 crioulo & 16 a 38 & $303 \$ 168$ \\
\hline 07 & 10 & Masculino & Africanos & 18 a 28 & $303 \$ 168$ \\
\hline 08 & 30 & Masculino & Africanos & 20 a 37 & $303 \$ 168$ \\
\hline 09 & 44 & Masculino & Angolas, Minas e Cabos-Verdes & 19 a 30 & $320 \$ 000$ \\
\hline
\end{tabular}

Fonte: ACSM, LN 08, 07/09/1718.

Legenda: A - nº de escravos; B - Valor médio em real.

A exceção da linha 09, todos os demais escravos foram avaliados em preço menor daqueles detectados na tabela 4. Não obstante, estavam bem acima daqueles oferecidos pelos inventários. Vale destacar os escravos pertencentes à linha 05. De idade adulta, esses nove cativos tiveram sua ocupação detalhada na fonte, tratava-se de mineiros, ou seja, empregados nas atividades de minerar, cujo valor médio foi o primeiro a bater na casa de $300 \$ 000$ milréis. Antes deles, os de maior valor foram aqueles representados na linha 01, dentre os quais havia, por exemplo, Pascoal Mulato alfaiate, Raimundo Angola barbeiro, Thomas Mulato sapateiro e Francisco Angola alfaiate. Provavelmente, o menor valor esteja correlacionado à ocupação dos cativos, donde se conclui escravos ocupados em minerar poderiam valer mais. Uma vez que tenhamos uma noção relativamente boa acerca dos preços dos escravos, passo a analisálos com base nos inventários.

A concordar com os dados apresentados por Laird Bergad acerca do comportamento dos preços dos escravos masculinos de 15 a 40 anos em Vila do Carmo (Mariana) e Vila Rica (Ouro Preto), podemos observar as seguintes variações: de 1715 até 1725, os escravos passaram de $200 \$ 000$ para $250 \$ 000$, seguido de uma queda até 1735 , quando registraram cerca de $185 \$ 000$. Apresentaram uma tendência de alta, com oscilações, até 1750, ocasião na qual custavam pouco mais de $250 \$ 000$. A partir de então, um contínuo declínio até início do século XIX, quando entram em curva ascendente. Com flutuações um pouco maiores, a curva dos preços das escravas na mesma idade apresentou idêntico perfil. ${ }^{24}$

Bergad respeitou as alterações na relação oitava/real quando efetuou BERGAD, Laird. Escravidão e história econômica: demografia de Minas Gerais, 1720-1888. São Paulo: EDUSC, 2004. p. 278-279. as conversões dos valores dados em oitavas. Com isso, as curvas de preço apresentadas pelo autor não permitem compreender o comportamento do mesmo, mas tão somente identificar os momentos em que a oitava correspondeu a este ou aquele valor em real. Em 1725, os preços caem, pois uma oitava passou de $1 \$ 500$ a $1 \$ 200$. A partir de 1735 , inicia-se a conjuntura na qual seu preço fechou em $250 \$ 000$ por volta de 1750, período no qual a oitava voltou a valer $1 \$ 500$. Desde este momento, tem-se a curva decrescente, e a uma oitava equivalia a $1 \$ 200$. Não custa lembrar, a estrutura da pose de escravos não apresentou variações até 1770. 0 que causaria estranheza tendo em conta este comportamento do preço dos escravos.

Por outro lado, a disposição dos preços dos escravos deflacionando o valor do real apresenta um quadro muito mais condizente quer com as tendências reveladas nos livros de nota (tabela 4), com o assentamento natural da sociedade após o alvoroço inicial proveniente das descobertas 
auriferas e mesmo com as variações no valor da oitava ao longo da primeira metade do século XVIII. Na construção do gráfico abaixo, relacionei em separado os escravos do sexo masculino e do feminino compreendidos entre 15 e 40 anos, ou seja, o mesmo grupo analisado pelo autor. 0 resultado pode ser observado no gráfico 2.

Gráfico 2 - Valor médio dos escravos adultos (15-40 anos) no termo de Vila do Carmo, 1713-1756.

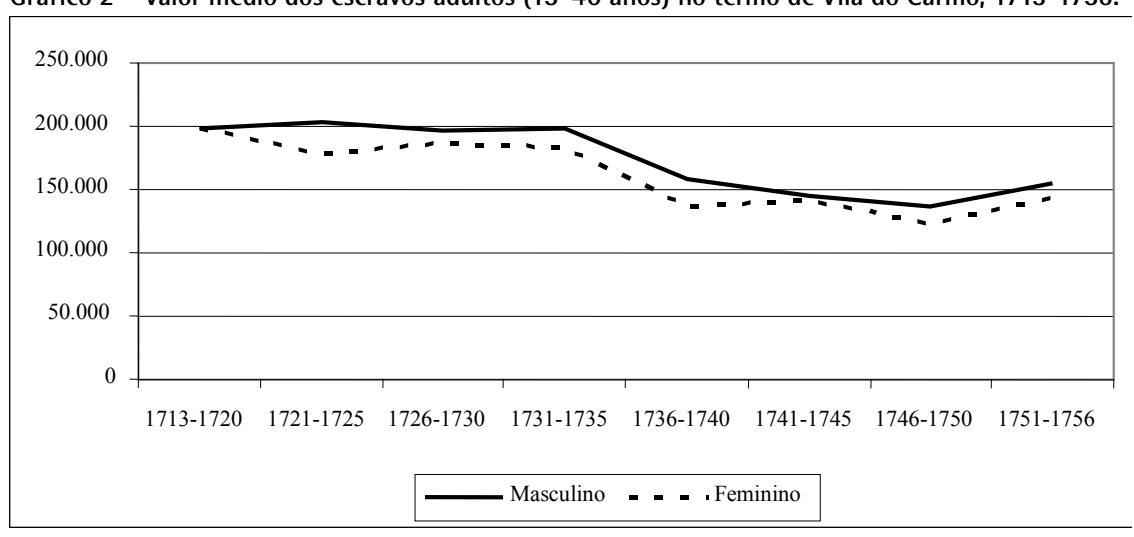

Fonte: $\mathrm{ACSM}, \mathrm{IPM}, 1^{\circ}$ e $2^{\circ}$ oficios.

As diferenças em relação às tendências apresentadas por Bergad são nítidas. Primeiro não se observa a queda entre 1725 e 1735, mas sim a manutenção dos preços, o que está em plena conformidade com os dados apresentados na tabela 4, não obstante as diferenças em números absolutos. 0 aumento dos preços entre 1735 e 1750 com intervalo em meados da década de 1740 igualmente não é percebido. Ao contrário, a curva nesse momento é descendente. Por fim, a contínua queda nos preços iniciada na década de 1750 deu vez a um ligeiro aumento nos mesmos.

Conforme já enunciado, a estabilidade até a década de 1735 estava relacionada com a capacidade do termo de absorver a oferta de mão-deobra escrava. A despeito de o valor da oitava ter sofrido uma redução em real, a quantidade de oitavas necessárias para se comprar um escravo não sofreu maiores alterações. Ou seja, mesmo com uma redução no valor do escravo - um escravo que custasse $300 \$ 000$ em 1720 valeira $240 \$ 000$ em 1727, por exemplo - seu valor em oitava permaneceu inalterado. No exemplo citado, o mesmo escravo teria sido avaliado em 200 oitavas nos dois momentos. Logo, esse abatimento no preço do cativo não concorreu para uma significativa reorientação na estrutura de posse (tabela 2).

Poder-se-ia argumentar que a faixa de 1-5 escravos passou de 15,38\% para $24,42 \%$ entre os dois primeiros momentos abordados na tabela. Sobre isso, aponto que entre 1731-740 e 1741-1750, quando uma oitava voltou a valer $1 \$ 500$, os $24,42 \%$ passaram para $28,48 \%$. Isto é, não foram as variações sofridas pela oitava - leia-se: intervenções da política econômica metropolitana - que regeram o acesso ao escravo, mas sim a várias conjunturas pelas quais passou a capitania de Minas Gerais, conjunturas essas cujas oscilações responderam aos niveis de produção do ouro. E isso explica o porquê de a estrutura da posse ter se mantido relativamente inalterada ao longo dos setenta primeiros anos do século XVIII.

A diminuição no preço do escravo perceptivel a partir de 1735 pode ser explicada em função do assentamento natural da sociedade, cuja demanda por cativos não era insaciável. Sendo o próprio rendimento das lavras que determinava o tamanho dos plantéis, é bem possivel que já em 1735 não houvesse muito mais para onde se expandir em termos de novos achados auriferos. Acerca da comarca de Vila Rica entre 1721 e 1722, escreveu Tarcísio Botelho: 
25

BOTELHO, Tarcísio Rodrigues. "População e Escravidão nas Minas Gerais, c. 1720". In: XII Encontro da Associação Brasileira de Estudos de População. Caxambu, 2000. p. 12.

\section{6}

BERGAD, Laird. Escravidão e história econômica: demografia de Minas Gerais, 1720-1888. São Paulo: EDUSC, 2004. p. 278.
27

SANTOS, Rafael de Freitas. "Devo que pagarei": sociedade, mercado e práticas crediticias na comarca do Rio das Velhas, 1713-1773. 2005. Dissertação (Mestrado). Belo Horizonte: Universidade Federal de Minas Gerais, 2005. p. 68. estamos falando do lugar que primeiro foi ocupado pelos mineradores, sede da segunda vila mais antiga da capitania (após a Vila do Carmo), estamos tratando de uma região já consolidada, com uma população estabelecida e com a ocorrência de poucas áreas novas se abrindo à mineração aurífera. 25

Eleger o ano de 1722 enquanto época plausivel para o fim de novos achados no termo de Vila do Carmo parece-me um tanto prematuro. Por meu turno, dilataria essa marca até o início da década de 1730. 0 motivo da periodização deve-se à queda em oitava registrada no valor dos escravos a partir de 1735 , muito provavelmente em função do aumento do valor da mesma para $1 \$ 500$. Ou seja, o termo não tinha mais a demanda de outrora, perdendo a capacidade de incorporar a oferta de escravos. Entre 1735-1739, o preço passou de aproximadamente $180 \$ 000$ para cerca de $225 \$ 000$ em 1740. Por volta de meados da década, já estava em 200\$000, fechando 1750 a $250 \$ 000.26$ Conforme o gráfico 2, o aumento no preço do escravo só viria a tomar vez em meados da década de 1750, fruto do retorno da oitava para $1 \$ 200$. Tratava-se de uma tentativa de igualar o preço aos niveis anteriores a 1735. Intento, aliás, infrutífero, como os próprios dados de Bergad demonstram para pós 1751.0 termo de Vila do Carmo já não apresentava a mesma capacidade de absorção de mão-de-obra cativa de outros tempos.

Isto posto, podemos avançar um pouco mais acerca do comportamento dos preços dos escravos no interior do termo de Vila do Carmo. Para tanto, apresento a tabela 6 , a qual traz o valor médio arrolado dos cativos inventariados consoante às diversas faixas de fortuna.

Tabela 6 - Preço médio em real dos escravos conforme faixas de fortuna no termo de Vila do Carmo, 1713-1756

\begin{tabular}{|l|c|c|c|}
\hline \multicolumn{1}{|c|}{ Faixa } & $1713-1730$ & $1731-1740$ & $1741-1756$ \\
\hline $1-999 \$ 999$ & $123 \$ 293$ & $110 \$ 900$ & $111 \$ 684$ \\
\hline $1: 000 \$ 000-1: 999 \$ 999$ & $146 \$ 888$ & $141 \$ 738$ & $119 \$ 296$ \\
\hline $2: 000 \$ 000-4: 999 \$ 999$ & $148 \$ 711$ & $147 \$ 155$ & $106 \$ 579$ \\
\hline $5: 000 \$ 000-9: 999 \$ 999$ & $167 \$ 936$ & $147 \$ 607$ & $120 \$ 160$ \\
\hline $10: 000 \$ 000-14: 999 \$ 999$ & $173 \$ 710$ & $127 \$ 252$ & $113 \$ 834$ \\
\hline $15: 000 \$ 000-19: 999 \$ 999$ & $200 \$ 003$ & $150 \$ 142$ & $109 \$ 446$ \\
\hline 20:000\$000-49:999\$999 & $180 \$ 691$ & $153 \$ 983$ & $113 \$ 279$ \\
\hline Acima de 50:000\$000 & & $147 \$ 867$ & \\
\hline Total & $166 \$ 780$ & $141 \$ 429$ & $113 \$ 056$ \\
\hline
\end{tabular}

Fonte: ACSM, IPM, $1^{\circ}$ e $2^{\circ}$ ofícios.

Novamente, se confirma a disposição geral de queda no valor dos escravos a partir da década de 1730, inclusive por faixa de fortuna. Contudo, o que importa observar na tabela acima é a variação no preço consoante as faixas de fortuna. Um fenômeno parecido pode ser observado na comarca do Rio das Mortes entre 1713 e 1773. Nos inventários insolventes, o preço médio do escravo era de $94 \$ 673$; naqueles cujas fortunas não ultrapassaram um conto de réis, $99 \$ 215$; na faixa de um conto a cinco contos, $109 \$ 088$; acima de cinco contos, $112 \$ 109$. Segundo o autor, o fato pode ser explicado "pela reposição constante de novas peças entre os grandes proprietários" e pela maior especialização dos escravos dos grandes plantéis. ${ }^{27}$

Porém, a tabela 6 complica um pouco as coisas, uma vez que nem sempre os inventários mais ricos detinham uma média superior aos seus precedentes. No primeiro período em apreço, os plantéis da faixa acima de vinte contos apresentaram um valor médio inferior ao da faixa de quinze a vinte contos. Nos demais períodos as variações são ainda maiores. Muito 
provavelmente essas oscilações teriam sido percebidas na comarca do Rio das Mortes caso as faixas de fortunas tivessem sido consideradas em detalhe, e não apenas classificando em "ricos" a enorme gama de montesmores acima de cinco contos de réis. De qualquer forma, passemos ao que realmente interessa.

Para uma melhor compreensão das variações nos preços dos escravos consoante a faixa de fortuna, faz-se necessário considerá-las à luz do perfil demográfico dos plantéis. Nesses termos, apresento as tabelas abaixo.

Tabela 7 - Estrutura da posse de escravos no termo de Vila do Carmo entre 1713 e 1730

\begin{tabular}{|c|c|c|c|c|c|c|c|c|c|}
\hline Faixa & A & B & C & D & E & F & G & H & I \\
\hline $1-5$ & 12 & 38 & 192 & 500 & 7,7 & 80,77 & 11,53 & $156 \$ 022$ & 10,52 \\
\hline $6-10$ & 24 & 187 & 164 & 272 & 19,88 & 78,26 & 1,86 & $154 \$ 564$ & 3,74 \\
\hline $11-20$ & 16 & 239 & 294 & 316 & 19,38 & 75,97 & 4,65 & $171 \$ 144$ & 9,62 \\
\hline $21-40$ & 17 & 457 & 341 & 382 & 9,67 & 77,33 & 13 & $166 \$ 375$ & 16,19 \\
\hline $41-$ & 9 & 485 & 352 & 359 & 8,93 & 77,45 & 13,62 & $169 \$ 047$ & 24,12 \\
\hline
\end{tabular}

Fonte: $A C S M, I P M, 1^{\circ}$ e $2^{\circ}$ oficios.

Legenda: A - no. de plantéis; B - no. de escravos; C - razão de masculinidade; D - razão de africanidade; E - \% de crianças da faixa (até 14 anos); F - \% de adultos da faixa (15-45 anos); $G$ - \% de velhos da faixa (acima de 46 anos); $\mathrm{H}$ - valor médio do escravo da faixa; I - \% de escravos sem valor declarado.

Tabela 8 - Índices efetivos por sexo e naturalidade, 1713-1730

\begin{tabular}{|l|c|c|c|c|c|c|}
\hline Faixa & \multicolumn{2}{|c|}{ Sexo } & $\begin{array}{c}\text { Índice } \\
\text { efetivo }\end{array}$ & \multicolumn{2}{|c|}{ Naturalidade } & $\begin{array}{c}\text { Índice } \\
\text { efetivo }\end{array}$ \\
\hline & Homem & Mulher & & Crioulo & Africano & \\
\hline $1-5$ & $160 \$ 207$ & $147 \$ 272$ & 27 & $90 \$ 480$ & $169 \$ 495$ & 69 \\
\hline $6-10$ & $165 \$ 911$ & $134 \$ 055$ & 66 & $101 \$ 271$ & $171 \$ 033$ & 61 \\
\hline $11-20$ & $183 \$ 282$ & $135 \$ 614$ & 100 & $828 \$ 57$ & $195 \$ 925$ & 100 \\
\hline $21-40$ & $167 \$ 692$ & $161 \$ 760$ & 12 & $128 \$ 504$ & $176 \$ 882$ & 43 \\
\hline $41-$ & $196 \$ 399$ & $168 \$ 465$ & 58 & $169 \$ 938$ & $196 \$ 074$ & 23 \\
\hline
\end{tabular}

Fonte: ACSM, IPM, $1^{\circ}$ e $2^{\circ}$ oficios.

$\mathrm{Na}$ construção da tabela 7, busquei incorporar os principais elementos os quais poderiam influenciar no valor médio dos escravos, a saber: a porcentagem de homens e mulheres, a porcentagem de crioulos e africanos e, por fim, a porcentagem consoante faixas etárias. Em relação à tabela 8 , 0 índice efetivo acerca do sexo foi calculado da seguinte forma: realizei a subtração entre os preços dos homens e das mulheres, a maior diferença foi tomada por valor base. Da mesma forma procedi para com o índice por naturalidade, subtraindo os crioulos dos africanos.

Conforme as tabelas acima, podemos perceber que ocorreu uma leve diminuição no preço médio do escravo na passagem do plantel de 1-5 ao de 6-10. Conforme o comportamento da razão de masculinidade, o valor médio poderia ter apresentado uma queda maior, já que a taxa declinou de 192 para 164. Contudo, a índice relativo ao sexo apresentou a segunda maior marca (tabela 8), evidenciando que a despeito de a taxa ter caído, a diferença entre o preço do homem e da mulher aumento 144\%. Percebese que a taxa de africanidade pouco interferiu na variação do valor médio, mesmo tendo apresentado um decréscimo violento. A explicação reside no aumento de $158 \%$ das crianças concomitante à forte diminuição na porcentagem dos velhos. Ou seja, o forte aumento dos crioulos referiu-se às crianças, as quais apresentam um valor não muito elevado. Para além, o índice acerca da naturalidade apresentou uma queda, o que concorreu para inibir uma redução maior entre os valores médios dos dois plantéis.

Ao compararmos os preços médios dos plantéis de 6-10 e 11-20 percebemos a maior variação entre todos os plantéis, um aumento de quase vinte 
mil réis. Esse aumento pode ser facilmente explicado. Os percentuais etários mantiveram-se estáveis, o que acarreta em suas exclusões da equação.

Além de a taxa de masculinidade ter apresentado uma elevação de 79\%, a faixa de 11-20 deparou-se com o maior índice acerca do gênero, ou seja, aumentaram os homens exatamente quando o preço deles e das mulheres conheceu sua mais dilatada diferença. 0 mesmo pode ser observado para a razão de africanidade e o índice de naturalidade. Assim sendo, a redução no valor médio dessa faixa para a seguinte seria de ser esperada, mesmo por que ocorreu um aumento no percentual de velhos e uma diminuição no de crianças. Tal diminuição só não foi maior em função de alguns contrapesos. A menor diferença entre os preços dos homens e das mulheres foi registrada no plantel de 21-40 (tabela 8). Longe de evidenciar uma redução no valor dos homens, o índice apontou uma elevação no preço das mulheres, não obstante sua menor participação nos plantéis, conforme demonstra o aumento de $16 \%$ na razão de masculinidade. Da mesma forma, embora 0 indice da naturalidade tenha sofrido uma redução, houve um aumento no valor dos crioulos, malgrado o acréscimo na taxa de africanidade.

Por fim, pode ser verificado um acréscimo no preço médio dos cativos entre o plantel de 21-40 e aqueles acima de 41 . Novamente as porcentagens etárias mantiveram-se estáveis, o que transfere a explicação para os vetores de gênero e naturalidade. De saída, percebemos um aumento na razão de masculinidade. Acrescentando a isso o fato de tanto o valor médio dos homens, quanto o das mulheres ter passado por um acréscimo, o índice de 58 verificado para a faixa na tabela 8 confluiu para o aumento no preço médio do plantel. 0 que contribuiu para que a elevação no valor médio não tenha sido maior foi o comportamento da naturalidade. Conforme pode ser notado, conquanto o índice de naturalidade da faixa acima de 41 escravos revelou um aumento geral nos preços dos crioulos e dos africanos, a razão de africanidade decresceu (tabela 7).

Contra uma possível alegação segundo o qual o alvorecer das minas não seria um momento privilegiado para o estudo acima empreendido, realizei a mesma análise para o período de 1741 a 1756. 0 resultado pode observado a seguir.

Tabela 9 - Estrutura da posse de escravos no termo de Vila do Carmo entre 1741 e 1756

\begin{tabular}{|l|l|l|l|l|l|l|l|l|l|}
\hline \multicolumn{1}{|c|}{ Faixa } & A & B & C & D & E & F & G & H & \multicolumn{1}{c|}{ I } \\
\hline $1-5$ & 43 & 120 & 224 & 471 & 14,29 & 82,14 & 3,57 & $121 \$ 502$ & 4,16 \\
\hline $6-10$ & 33 & 246 & 266 & 296 & 18,43 & 73,27 & 8,3 & $123 \$ 198$ & 10,16 \\
\hline $11-20$ & 28 & 425 & 261 & 262 & 16,67 & 79,02 & 4,31 & $122 \$ 109$ & 4,23 \\
\hline $21-40$ & 31 & 930 & 299 & 214 & 18,36 & 63,51 & 18,13 & $113 \$ 864$ & 9,13 \\
\hline $41-$ & 16 & 1138 & 313 & 237 & 15,57 & 67,22 & 17,21 & $116 \$ 150$ & 2,37 \\
\hline
\end{tabular}

Fonte: $\mathrm{ACSM}, \mathrm{IPM}, 1^{\circ}$ e $2^{\circ}$ ofícios.

Legenda: $A$ - no . de plantéis; $B$ - $n^{\circ}$. de escravos; $C$ - razão de masculinidade; $D$ - razão de africanidade; $E$ - \% de crianças da faixa (até 14 anos); F - \% de adultos da faixa (15-45 anos); G - \% de velhos da faixa (acima de 46 anos); $\mathrm{H}$ - valor médio do escravo da faixa; I - \% de escravos sem valor declarado.

Tabela 10 - Índices efetivos por sexo e naturalidade, 1741-1756

\begin{tabular}{|l|c|c|c|c|c|c|}
\hline \multicolumn{1}{|c|}{ Faixa } & \multicolumn{2}{|c|}{ Sexo } & $\begin{array}{c}\text { Índice } \\
\text { efetivo }\end{array}$ & \multicolumn{2}{c|}{ Naturalidade } & $\begin{array}{c}\text { Índice } \\
\text { efetivo }\end{array}$ \\
\hline & Homem & Mulher & & Crioulo & Africano & \\
\hline $1-5$ & $123 \$ 591$ & $116 \$ 916$ & 23 & $92 \$ 346$ & $123 \$ 591$ & 50 \\
\hline $6-10$ & $128 \$ 181$ & $110 \$ 154$ & 63 & $77 \$ 025$ & $139 \$ 279$ & 100 \\
\hline $11-20$ & $124 \$ 564$ & $115 \$ 247$ & 32 & $104 \$ 618$ & $128 \$ 402$ & 38 \\
\hline $21-40$ & $120 \$ 155$ & $97 \$ 196$ & 80 & $90 \$ 023$ & $123 \$ 288$ & 53 \\
\hline $41-$ & $123 \$ 034$ & $94 \$ 420$ & 100 & $92 \$ 743$ & $125 \$ 193$ & 52 \\
\hline
\end{tabular}

Fonte: $\operatorname{ACSM}, I P M, 1^{\circ}$ e $2^{\circ}$ ofícios. 
A metodologia empregada na construção das tabelas acima foi exatamente a mesma daquela presente nas tabelas 7 e 8 Nesse sentido, não há necessidade de tecer maiores considerações acerca da matéria. Passando à análise propriamente dita, observa-se um ligeiro aumento no valor médio dos escravos pertencentes ao plantel 6-10 em relação ao 1-5. 0 motivo capital para tanto se encontra no índice de naturalidade. Não obstante 0 aumento da participação dos crioulos nos plantéis de 6-10 - o que pode ser atestado na diminuição da taxa de africanidade - , o preço dos crioulos atingiu sua menor marca na faixa 6-10 exatamente a mesma faixa na qual o preço dos africanos alcançou seu pico, não por nada o índice do plantel foi o base (tabela 10). As variáveis de gênero igualmente ofereceram condições necessárias à ascensão dos preços. 0 aumento na razão de masculinidade foi seguido por uma elevação no valor dos homens e de uma redução no preço das mulheres, o que ocasionou o segundo maior indice de gênero. 0 aumento no valor médio do plantel só não foi maior em função dos percentuais etários: a participação dos adultos enfraqueceu simultaneamente à intensificação das crianças e dos velhos, bem mais baratos dos que os adultos.

A irrisória queda nos preços do plantel de 6-10 em relação ao de 11-20 é explicado pelas compensações entre as variantes em análise. Observando o comportamento etário, seriamos levados a crer na subida dos preços, uma vez que diminuiu os percentuais dos velhos e das crianças e aumentou a participação dos adultos. Mas não é o que se verifica. A explicação para a sutil involução no valor médio do plantel de 11-20 reside tanto no comportamento do gênero, como da naturalidade. $A$ cerca do primeiro, a diminuição da razão de masculinidade aponta para a maior participação das mulheres frente aos homens, e o índice de gênero demonstra uma redução na diferença de preços entre os sexos, signo do acréscimo do valor da mulher e decréscimo no do homem. Logo, aumentou a participação de uma variável a qual concorreu para a redução no preço médio do plantel. Exatamente o mesmo se passou com a taxa de africanidade e com o indice de naturalidade.

A oscilação mais abrupta no periodo foi verificada na passagem da faixa de 11-20 para a de 21-40, em cujo momento os preços dos escravos relativos aos maiores plantéis sofreram uma redução de quase $10 \$ 000$. Os motivos para tanto são simples. Sem contar a maior participação das crianças, o percentual de adultos conheceu sua menor marca ao mesmo tempo em que os velhos atingiram o topo. Se isso não bastasse, malgrado o aumento da razão de masculinidade, a tabela 10 apresenta uma queda geral nos preços dos escravos da faixa, quer por gênero, quer por naturalidade. A subida no valor médio dos cativos detectado na faixa acima de 41 está atrelada a uma tendência mais ampla de ascensão das variáveis determinantes: o percentual de adultos voltou a subir, assim como a razão de masculinidade - o preço do escravo masculino passou por uma elevação, ao inverso do feminino (tabela 10) - e a taxa de africanidade - tanto os crioulos, como os africanos tiveram seus valores acrescidos.

Fica patente não ter sido a maior ou menor reposição de cativos e a especialização dos mesmos os principais fatores a determinar as oscilações em seus valores conforme o tamanho dos plantéis. Uma séria de outras variantes deve ser posto em conta para se tentar uma aproximação dos reais vetores de tal processo. Contudo, a análise acima não se presta somente a esta comprovação. Por exemplo, ajuda a compreender a compo- 
28

FLORENTINO, Manolo Garcia. Em Costas Negras: uma história do tráfico de escravos entre a África e o Rio de Janeiro. São Paulo: Cia. das Letras, 1997. p. 102.

\section{9}

FLORENTINO, Manolo Garcia. Op.Cit. p. 102-103. Ver também, FRAGOSO, João \& FLORENTINO, Manolo. 0 arcaísmo como projeto: mercado atlântico, sociedade agrária e elite mercantil em uma economia colonial tardia. Rio de Janeiro: Civilização Brasileira, 2001. p. 146-148.

\section{0}

No que concerne às faixas de fortuna, considerei pobres as faixas compreendidas entre 11:999\$999, intermediários entre 2:000\$00014:999\$999 e ricos acima de 15:000\$000. Em função do dinamismo da sociedade em questão e a fim de empreender um estudo mais pormenorizado das faixas de fortuna, subdividi os intermediários em médio-pobres (2:000\$000-4:999\$999), médios (5:000\$000-9:999\$999) e médio-ricos (10:000\$000-14:999\$999). Para tanto, utilizei por critério o tamanho médio dos plantéis.

31

ALMEIDA, Carla. Alterações nas unidades produtivas mineiras: Mariana - 1750-1850. 1994. Dissertação (Mestrado) Niterói: Universidade Federal Fluminense, 1994. p. 178. sição da riqueza nos inventários conforme as faixas de fortuna, pois na medida em que se tem clara noção das variações no preço do escravo por plantel, é possivel um olhar bastante preciso acerca do peso do cativo em cada faixa.

Por fim, gostaria de destacar o peso do preço do cativo na disseminação e na estrutura da posse dos mesmos. No termo de Vila do Carmo, embora tenha influenciado, o valor do escravo não foi o fator determinante para a disseminação e estrutura da posse. Já vimos que ambas não apresentaram maiores variações até o final do século XVIII, sem embargo de o preço do cativo ter passado por várias oscilações. Por outro lado, o arrefecimento da produção aurifera acarretou significativas mudanças na estrutura e na disseminação da posse de escravos.

Nas primeiras décadas do século XIX no Rio de Janeiro, a propriedade escrava era consideravelmente difundida, inclusive entre os mais pobres. A explicação para tanto reside, verdadeiramente, naquilo denominado "produção social do escravo", ou seja,

a soma dos gastos, em horas/trabalho, necessários à produção e manutenção do homem desde seu nascimento até o instante em que ele se transformava em escravo. Era seu grupo familiar e, em última instância, sua comunidade quem efetivamente o produzia. Antes da mutação em cativo, o individuo era, portanto, o repositório de milhares de horas/trabalho despendidas por toda a comunidade (Meillassoux, 1985). Ora, como a violência representava o meio fundamental por meio do qual o homem era retirado de sua comunidade e escravizado, o custo de sua produção social não era de maneira alguma reposto. ${ }^{28}$

A sociedade africana arcava com o ônus da produção social do escravo e com o prejuizo da sua captura; dada a não equivalência residente no cerne das relações de troca do escravo por outras mercadorias. Essa não equivalência impregnava todas as etapas da circulação do cativo.

\footnotetext{
A captura significava a apropriação de trabalho alheio que jamais seria pago. Isto dava margem a que todos os elos de intercâmbio que se processavam desde o interior da África até a empresa escravista americana se caracterizassem pela não-equivalência. Era não equivalente em termos de horas/trabalho, por exemplo, o escambo de um escravo por dois ou três mosquetões, por dez ou doze fardos de têxteis, ou ainda por quatro ou cinco barris de aguardente. Como em uma correia de transmissão, esta não-equivalência se transportava para as etapas de circulação da mercadoria viva na América, quando a compra do cativo em dinheiro não expressava seu real valor social. A guerra, sinônimo aqui da violência fundadora do escravo (...) esta mesma violência também determinava não somente os baixos preços do cativo na América - e, por isso mesmo, a própria extensão social da escravidão -, como também condicionava as estratégias de rentabilidade da empresa traficante. 29
}

No que concerne ao termo de Vila do Carmo, creio ser esta a explicação para o aumento da participação dos mais pobres 30 na posse de escravos a partir de 1780 (tabela 3), quando a extração do ouro apresentava níveis de produção os quais não mais comportavam a estrutura de posse mantida até então. Diga-se de passagem, a década de 1780 marca o momento de ascensão dos preços. Em 1800, um escravo entre 20 e 30 anos custava 116\$554; em 1820, 157\$083; e em 1850, 519\$583.31

Contudo, o reordenamento na estrutura da posse somente foi possivel em função da desaceleração na produção aurífera. Até então, era o rendimento da lavra, e não preço do cativo, o que explicava a alta disseminação 
da posse entre os mais pobres. Conforme já vimos, a grande maioria dos inventariados possuia plantéis com mais de 11 escravos. Porém, apenas $20 \%$ deles eram mineradores. 0 grosso da população estava às voltas com o mercado de abastecimento, quer das unidades produtivas mineradoras, quer dos demais segmentos residentes no termo ou que por lá chegavam e partiam ocupados de seus negócios. E essa era a forma encontrada por esses indivíduos para terem seu acesso ao ouro facultado.

Em dado momento ao longo do texto, escrevi que o estudo da estrutura da posse de escravos prestava-se a vários fins. Do que foi até aqui defendido, a estrutura da posse revelou, na primeira metade do século XVIII, uma sociedade cujo acesso ao seu bem primeiro, o cativo, não era tão desigual conforme se poderia supor. Ao contrário, verificou-se que mesmo os mais pobres detinham plenas condições de tornarem senhores de outros homens e mulheres, ainda que em conjunturas nas quais os preços dos escravos tivessem atingindo seu ápice.

Recebido para publicação em julho de 2007

Aprovado em outubro de 2007 